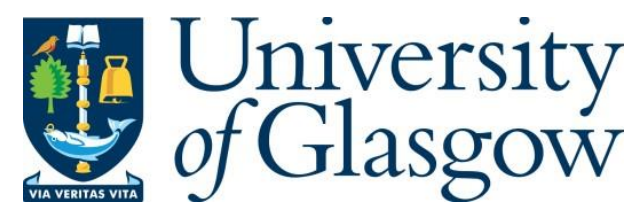

Ochieng, F.X., Hancock, C.M., Roberts, G.W. and Le Kernec, J. (2018) A review of ground-based radar as a non-contact sensor for structural health monitoring of infield wind turbines blades. Wind Energy, 21(12), pp. 1435-1449.

There may be differences between this version and the published version. You are advised to consult the publisher's version if you wish to cite from it.

This is the peer reviewed version of the following article Ochieng, F.X., Hancock, C.M., Roberts, G.W. and Le Kernec, J. (2018) A review of ground-based radar as a non-contact sensor for structural health monitoring of in-field wind turbines blades. Wind Energy, 21(12), pp. 1435-1449, which has been published in final form at http://dx.doi.org/10.1002/we.2252. This article may be used for non-commercial purposes in accordance with Wiley Terms and Conditions for Self-Archiving.

http://eprints.gla.ac.uk/163945/

Deposited on: 17 July 2018

Enlighten - Research publications by members of the University of Glasgow http://eprints.gla.ac.uk 


\title{
A review of ground-based radar as a noncontact sensor for structural health monitoring of in-field wind turbines blades
}

\author{
Francis Xavier Ochieng ${ }^{1}$, Craig Matthew Hancock ${ }^{2}$, Gethin Wyn Roberts ${ }^{3}$, Julien Le Kernec ${ }^{4}$ \\ ${ }^{1}$ International Doctoral Innovation Centre, University of Nottingham Ningbo China, Ningbo, China \\ ${ }^{2}$ Department of Civil Engineering, University of Nottingham Ningbo China, Ningbo, China \\ ${ }^{3}$ The University of the Faroe Islands, Tórshavn, Faroe Islands \\ ${ }^{4}$ The University of Glasgow, Glasgow, UK
}

\section{Abstract}

Ground-based radar (GBR) are increasingly being used either as a vibration-based or as guided-wavebased structural health monitoring (SHM) sensors for monitoring of wind turbines blades. Despite various studies mentioning the use of radar as transducer for SHM, a singular exclusive review of GBR in blade monitoring may have been lacking.

Various studies undertaken for SHM of blades using GBR have largely been laboratory-based or with actual wind turbines in parked positions or focussed on the extraction of only specific condition parameters like frequency or deflection with no validation with actual expected operating data. The present study provides quantitative data that relates in-field monitoring of wind turbines by GBR with actual design operating data. As such it helps the monitoring of blades during design, testing, and operation. Further, it supports the determination of fatigue damage for in-field wind turbine blades especially those made of composite materials by way of condition parameters residuals and deflection.

A review of the two GBR-SHM approaches is thus undertaken. Additionally, a case study demonstrating its practical use as a vibration-based noncontact SHM sensors is also provided. The study contributes to the monitoring of blades during design, testing, and operation. Further, it supports the determination of damage detection for in-field wind turbine blades within a 3-tier SHM framework especially those made of composite materials by way of condition parameter residuals of extracted modal frequencies and deflection.

\section{Abbreviations}

CP, condition parameters (as unbalanced parameters in this study); CSLDV, continuous-scan laser Doppler vibrometer; EoCs, environmental and operational conditions; FMCW, frequency-modulated continuous wave; FRPC, fibre-reinforced polymer composite; GBNW-SAR, ground-based noise waveform SAR; GBR, ground-based radar; GNSS, Global Navigation Satellite System; HT, hypothesis testing; IDIC, International Doctoral Innovation Centre; JTF, joint time frequency; LDV, laser Doppler vibrometer; SAR, synthetic aperture radar; SFCW, stepped frequency continuous wave; SHM, 
structural health monitoring; SL-FMCW, step linear frequency-modulated continuous wave; UWB, ultra-wideband; VNA, vector network analyser.

\section{Background}

The increase by $22 \%$ in cumulative installed wind energy capacity on an annual basis, ${ }^{1}$ though increasing share of clean energy of energy, may also be fraught with challenges. First, the increasing rotor sizes to capture more energy may have added issue of aeroelasticity and flutter ${ }^{2}$ to the already existing load analysis of fatigue and ultimate strength loads. The second is the emerging challenge of structural health monitoring (SHM) of blades particularly aeroelasticity as blade become much longer, increasing flap wise vibrations. ${ }^{2}$ With further increases in blade lengths, the torsional frequencies tend to reduce, leading to flutter. Unfortunately, as of today, aeroelasticity modelling in most wind turbine numeric models remains at basic principles. ${ }^{2}$ Highlighting the need to acquire a comprehensive understanding of the blades while in actual operation, such as may be brought by a sensor that does not change the blades structure, weight or shape need to be used, lending credence to the possibility of noncontact sensors.

The foregoing when coupled with environmental and operating conditions (EoC), in which wind turbines blades operate, may be one of the reasons for many blade failures. Environmental and operational conditions including unbalanced blades, defined as relative blade angle deviations $\left(>0.3^{\circ}\right)$ with respect to the set value, ${ }^{3}$ acid rain that deteriorates glass fibre polymer composite blades, ${ }^{4-6}$ lightning, and varying changes in climate ${ }^{7}$ impact annual variability of wind resourcesaffecting wind turbine total loads and hence altering the conditions and affecting the lifetime of existing turbines.

It is found by Ciang et al ${ }^{8}$ that blades have a $74.79 \%$ failure rates as compared with other turbine components, while other studies, ${ }^{90}$ point out that 1 in 8 and 1 in every 61 wind turbine faced bladerelated down times or failures, respectively, implying $12.5 \%$ and $2 \%$ of the 300000 existing wind turbines in 2018 will face blade related downtimes, failure, and damage. ${ }^{11}$

In detecting the damage by SHM, a study by Van Overschee and De Moor ${ }^{12}$ suggest 2 most widespread methods in the last 2 decades. These are the differential guided wave-based signal analysis as being and vibration-based damage detection (VBDD).

In Loh et $\mathrm{al}^{13}{ }^{13}$ VBDD is divided into model based and nonmodel based. Detecting damage in nonmodel-based approach requires analysing measurement of the damaged and undamaged state for a level 2 damage detection, whilst the model-based compares and correlates an analytical framework like finite element model with measurements to detect level 2 damage. In both approaches, some key principles are employed:

1. Deviation from the normal range of dynamic response for the damage sensitive features of the structure (blade tip deflection and natural frequencies) will be indicative of potential or pre-existing damage. In this, a range is defined, because sensors will have different accuracy levels and may also be affected by the EoC like temperatures, humidity, dust, rotations, and electromagnetic (EM) interferences among others.

2. Data analysis through multisensor or multisources reduces errors and allows formation of an analysis matrix and extraction of SHM condition parameters (CP) that enable structural damage assessment. Use of data from all sensors for SHM CP in a Hankel matrix enables the 
(a) detection, (b) location, and (c) quantification of damage using stochastic subspace identification. ${ }^{13}$

The widespread use of singular value decomposition (SVD) for structural damage detection by "comparing current sensor data to measurements taken from the healthy structure under varying EoC" is becoming widespread. ${ }^{12-14}$ This implies using measurement from 1 sensor can be compared with prior acceptable/operating ranges (tolerance) of dynamic characteristics of structure, such as changes in blade tip deflection range or modal frequencies to determine level 1 damage. Then, using approaches like fractal dimension or curvature methods a level 2 damage detection can be achieved. The level 2 damage detection actually locates the damage. ${ }^{13}$

For level 1 identification, contact sensors have historically played a major role. ${ }^{15-18}$ Noncontact sensors, especially when designing wind turbines and certifying them, their applications may have been limited to mainly in laboratory situations or for wind turbines in parked positions. ${ }^{619-25}$ No single work that particularly considers ground-based radar (GBR) may not be present yet. Consequently, a potential gap may exist for an exclusive review for SHM of blades using GBR. Further, no review may have applied GBR SHM within a clear 3-tier SHM framework for SHM level 1 damage detection.

Studies where the radar system is placed on the ground and used SHM of structures like bridges and buildings are available in literature ${ }^{26-28}$. What is key in these studies is that, firstly, damage is detected ${ }^{29-34}$ and secondly, a contact sensor like accelerometer ${ }^{35,36}$ that is attached to the structure may be used to validate the GBR results. In Muñoz et al and Corucci, ${ }^{37,38}$ the GBR is used to monitor a tower, while in other studies ${ }^{39,40}$ the radar is not in contact at all with the wind turbine but is demonstrated to acquire the deflection and modal frequencies. During the monitoring of the structure under movement, the GBR is fixed at the position on the ground and not moved at all.

Based on studies, ${ }^{12-14}$ one can also validate the GBR results using previous design data set of the wind turbine when in a healthy state. This increasingly widespread approach may be considered as use of SVD for structural damage detection. This suggests that GBR measurements can be validated using prior acceptable/operating ranges (tolerance) of dynamic characteristics of structure, such as changes in blade tip deflection range or modal frequencies to determine level 1 damage.

It has been suggested in certain literature ${ }^{36,40}$ that despite the increasing use of GBR for SHM, certain challenges have become evident. These include

- The GBR accuracy in some literature is not verified by laboratory test or in-field measurements campaigns.

- Accurate and extensive comparisons between time histories acquired from conventional sensors and GBR were not performed.

- No experimental evidence was provided that the resonant frequencies acquired from the GBR correspond to the dynamic characteristics of the investigated structures.

With a focus on SHM of wind turbine blades, this paper seeks to address two gaps in knowledge. That noncontact sensors can contribute towards SHM of structures under dynamic movement and may detect damage based on considering SHM damage detection as a 3-level process: level 1damage identification: Damage may be deemed to have occurred in a structure, if and when the SHM CP (modal frequencies, deflection, mode shape, etc) are extracted and shown to have deviated from what is deemed to be normal operating tolerances/state. 
Contact sensor achieve SHM level 1 damage identification by determining a baseline situation of say modal frequency, and then damage is introduced, and the sensor in principle, when it takes a new measurement, reveals a change in say modal frequency due to the damage. For the GBR, the design $\mathrm{CP}$ are compared with the current operating CPs to determine if damage has occurred. The design $\mathrm{CP}$ being considered as the baseline conditions. In bridge situations, the accelerometers provide the baseline conditions as an alternative approach to the previously mentioned SVD. Level 2-damage localization: In this case, the exact point where the damage has occurred is identified. Level 3fatigue life determination: based on levels 1 and 2, a calculation of the remaining useful life of the structure or expected structural failure can be done.

The GBR employs level 1 damage detection by identification of change of CP. This is demonstrated by the references previously given and further experimentally proved by the case study. ${ }^{39} \mathrm{~A}$ recent study demonstrates the use of radar for level 2 damage localization. ${ }^{41}$

From the foregoing, the novelty of the paper at hand are given by the following aspects, which also forms the goals of this work:

1. Present a critical comparative analysis of contact and noncontact sensors (Table 1) for wind turbine blade SHM.

2. Further, the article reviews the use of GBR as noncontact sensor for blade monitoring, particularly highlighting the EoCs conditions under which it was used. In this sense, it differentiates between vibration-based and guided wave SHM GBR transducers. As far as our literature review reveals, no such work has exclusively dealt with wind turbine blades using such a distinction.

3. Finally, the study concludes by a case study that demonstrates use of GBR for SHM based on results using model-based approach for level 1 damage detection. Many of the GBR results presented in literature are not for an in-field operating wind turbine, and for the few that are for actual wind turbines, no validation with contact nonmodel based or model based validation has been done. 

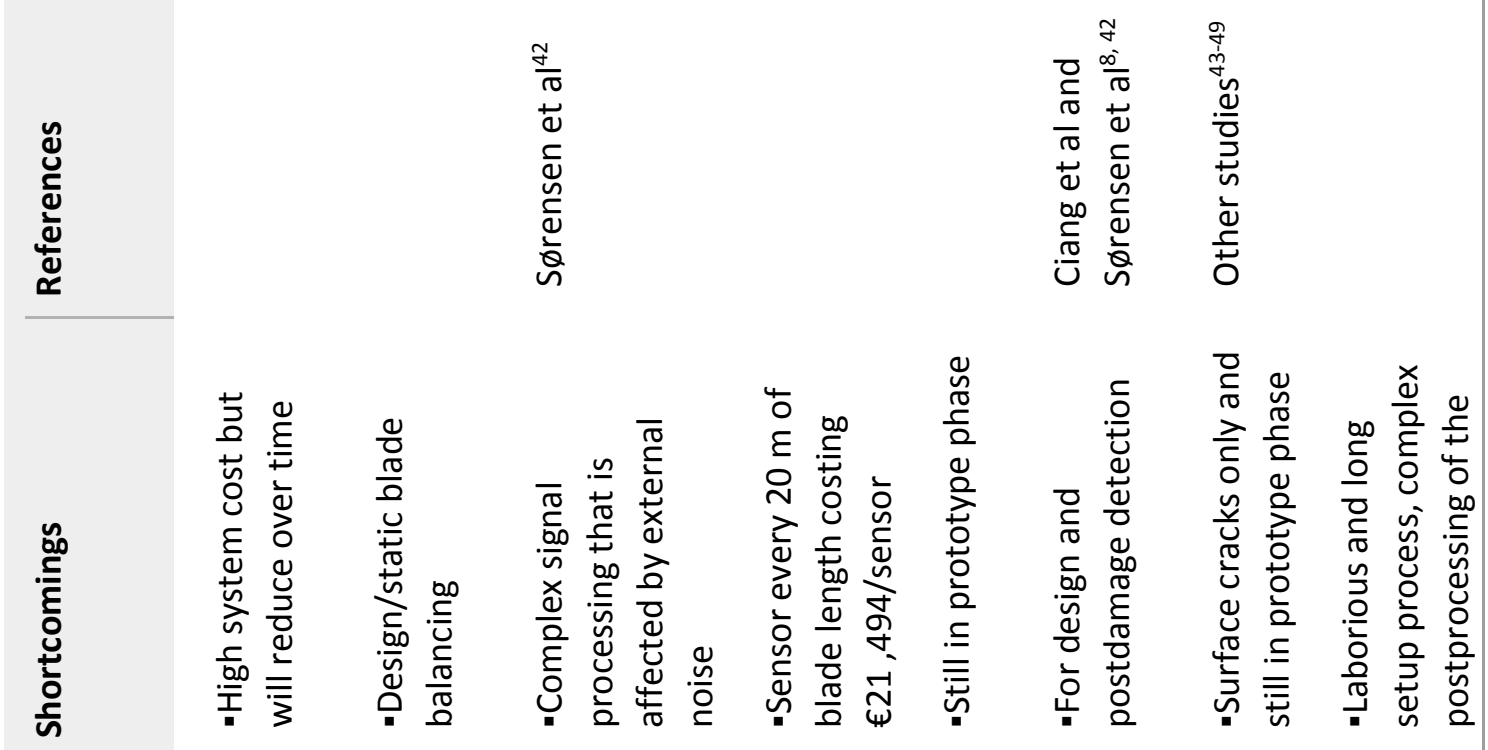

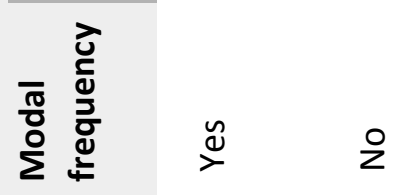

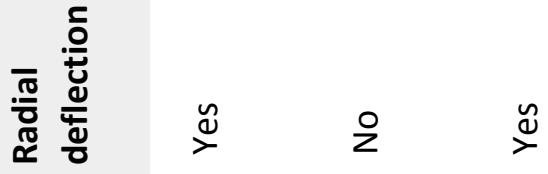

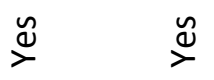

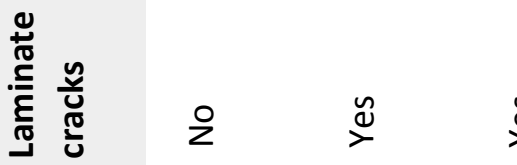

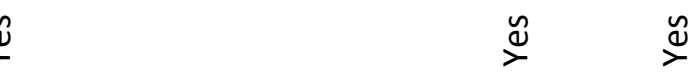

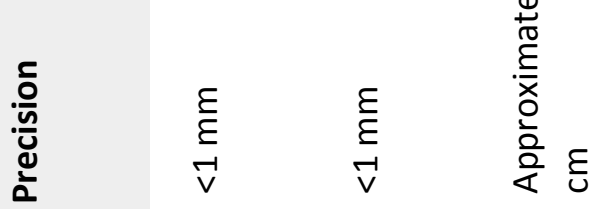

ते

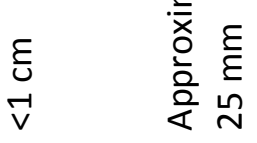

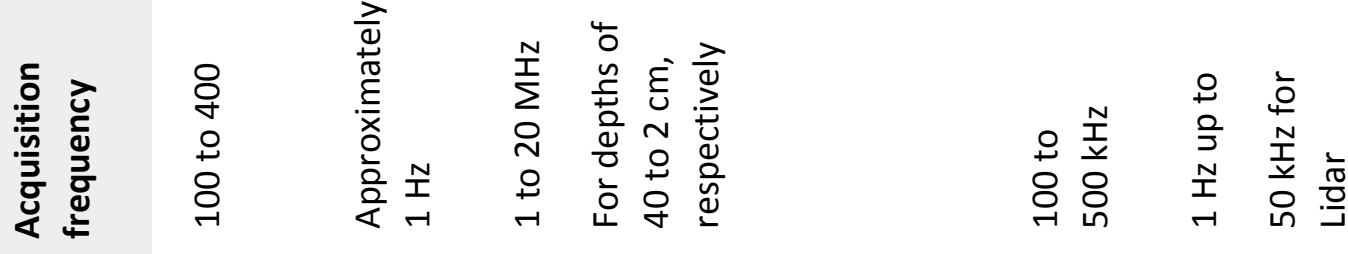

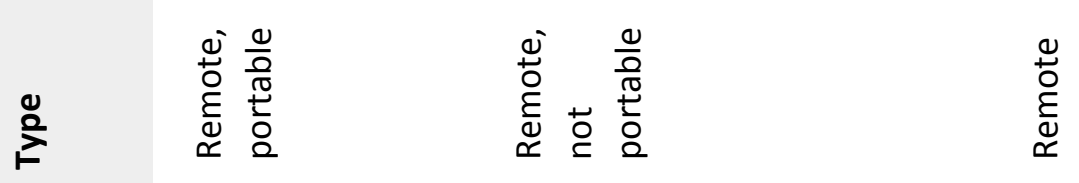

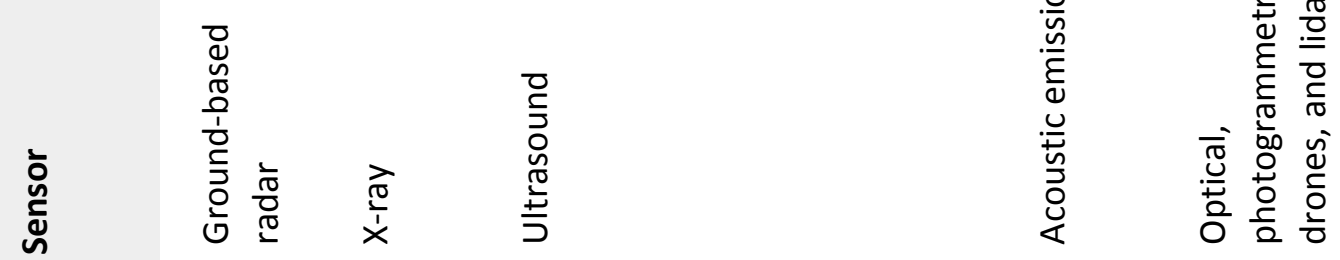




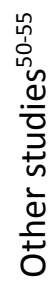

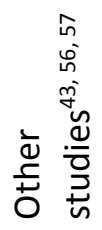

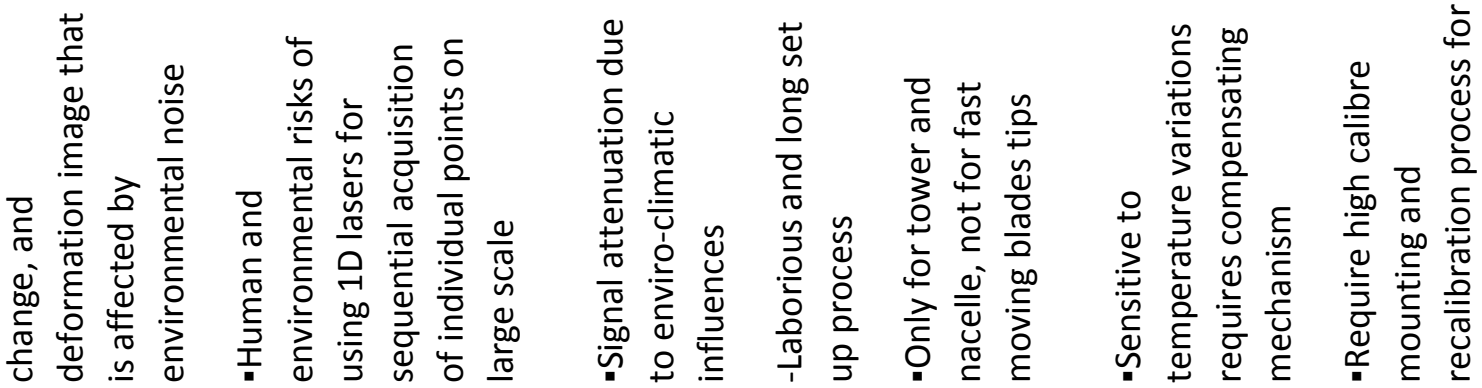

$\stackrel{1}{2}$

을

2

$\stackrel{n}{2}$

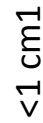

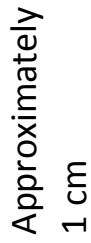

N

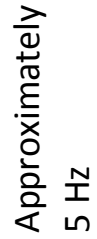

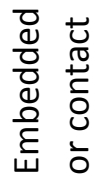

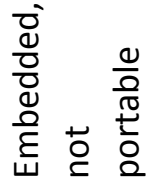

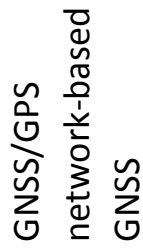

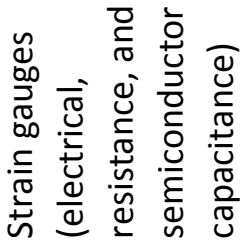




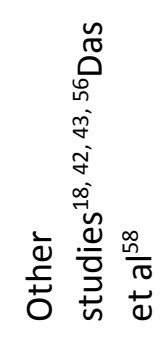

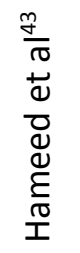

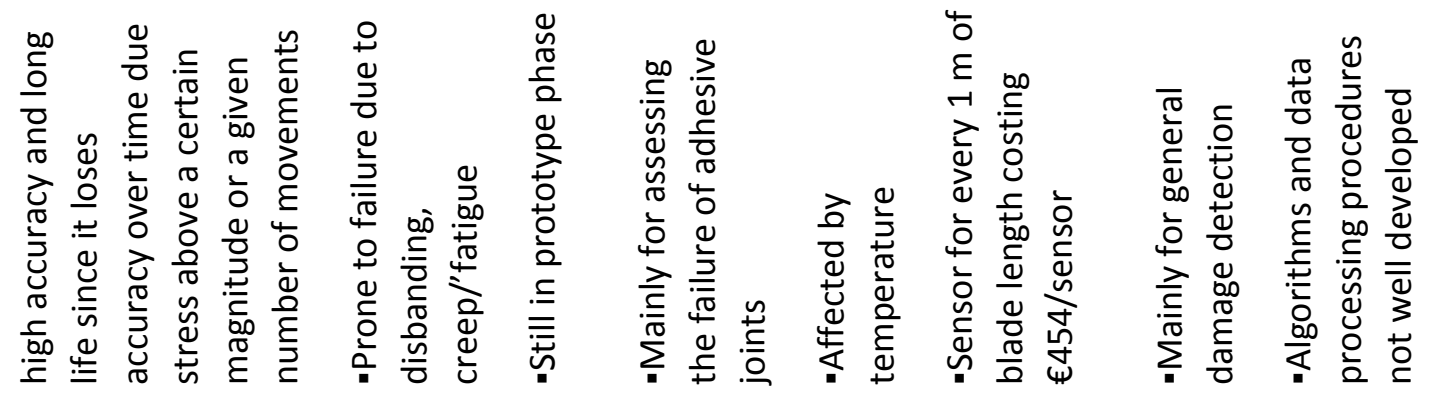

$\stackrel{\varrho}{\check{2}}$

$\stackrel{0}{\nu}$

$\stackrel{y}{\nu}$

운

$\xi$
$\xi$
$\vec{v}$

$\varepsilon$
$\vec{v}$

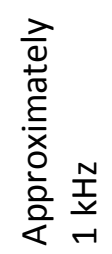

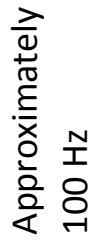

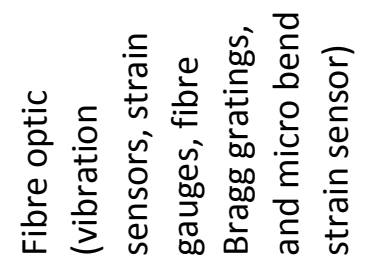

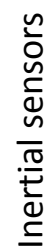




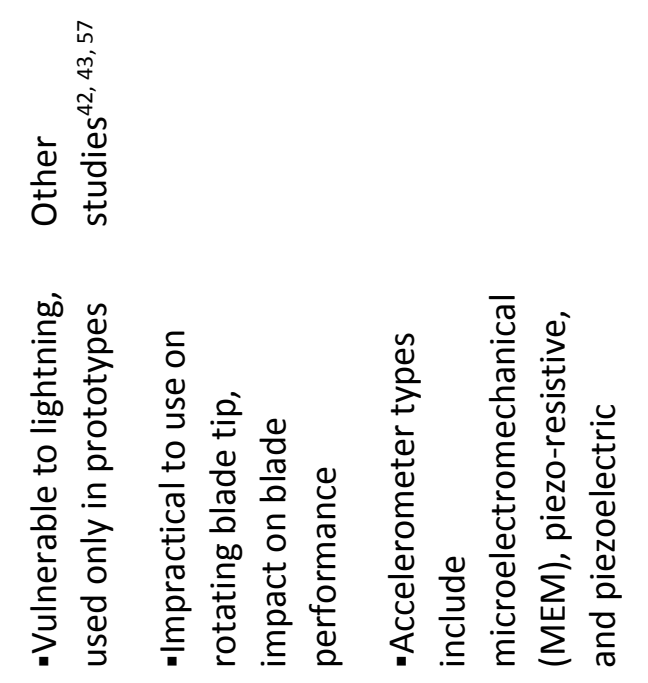

$\stackrel{\varrho}{\varnothing}$

$\stackrel{y}{x}$

운

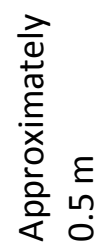

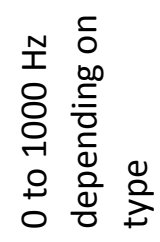

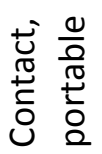

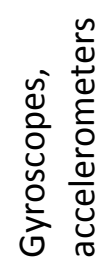


Consequently, damage detection in SHM may be considered at 2 levels. Level 1 (damage identification), where the $\mathrm{CP}$ are extracted and compared either with another sensor or from apriori healthy state data or from model to determine if there is deviation. Second is level 2 (damage location) where the damage is located. The GBR in Van Overschee and De Moor ${ }^{12}$ uses residual mapping, ie, compares a previous healthy state image of the structure with the current image to determine the location of the damage. The case study presented shows a level $1 \mathrm{SHM}$ that aims at only damage identification (level 1 ).

The remainder of this review and case study is organized in the following way: section 2introduces the 3-tier SHM, ${ }^{59,60}$ while section 3 provides the state of art review of contact and noncontact sensors used to determine blade's SHM CP. Section 4 then exclusively reviews GBR as an SHM transducer, and Section 5 presents the case study of use of GBR within the 3-tier framework. Section acknowledgements consequently concludes the paper and identifies further areas for more research.

\section{State of the Art in Classical Contact and Noncontact Sensors for Blade Monitoring}

Several approaches are used in determining the SHM of blades CP. These include time-frequency analysis methods, vibration-based methods, and voltage and current based methods. A study reviewing these methods ${ }^{61}$ concluded that vibration-based methods provide the best practices for wind turbines SHM. Consequently, the use of structural vibration ${ }^{62,63}$ of gearboxes, blades, and tower positioning ${ }^{3}$ provide a simple basis for measuring the unbalanced parameters for potential and pre-existing fatigue damage. A critical comparative analysis of these contact and noncontact sensors is explored in Table 1 with respect to their determination of in-field unbalanced vibrational parameters (radial displacement and modal frequency). ${ }^{15-18}$

\subsection{Direct and indirect contact-based sensors}

In other studies, ${ }^{64-66}$ the classical surveying sensors such as photogrammetric cameras, ${ }^{43-49}$ Global Positioning System receivers, ${ }^{50-52}$ network-based Global Navigation Satellite System, ${ }^{53-55}$ strain gauges, ${ }^{43,56,57}$ fibre optic and inertial sensors, ${ }^{18,42,43,56}$ levels, total stations, and theodolites are divided into geodetic and non-eodetic sensors. ${ }^{67,68}$ These classical embedded sensors are currently used to complement the traditional finite element analysis used to investigate eigen frequencies, tip deflections and stress-strain ( $\mathrm{S}-\mathrm{N}$ ) levels of composite wind turbine blades. ${ }^{43,69-71}$ Further, they are normally placed in locations where the damage is most likely to occur. ${ }^{10}$ Such locations include the blade root, spar cap, spar, splash zone of the tower, welded or bolted tripod joints, and lastly, 30\% to $35 \%$ and $70 \%$ from the blade root.

In other studies, ${ }^{63,72}$ other novel indirect contact approaches to determine unbalanced parameters using prognostic methods are indicated. They include gearbox monitoring using vibration analysis and time-series prediction, bearings acoustic emission, use of signature distances, and supervisory control and data acquisition (SCADA) data analysis. These, however, do not provide real-time monitoring of unbalanced parameters, as they depend on the structural vibrations or blade-tip speed to be high enough to trigger warning signals in the gearbox and bearings. Other innovative indirect contact-based sensors ${ }^{3,73-75}$ like visual blade examination, pitch angle measurements, holospectrum, and detection of mass imbalance for assessing unbalanced parameters have the demerit of relying on the sensor being embedded in the wind turbine, creating a challenge if the sensors cannot be accessed if it fails or limitations in moving the sensor from one turbine to another; 
furthermore, their application in real-time data collection and measurement of unbalanced parameters is difficult.

The challenges with the embedded and/or contact sensors when measuring blade-tip deflections and modal parameters are many, for instance, $(a)$ some require a laborious time-consuming installation and data collection process, $(b)$ it is unfeasible to set them up on the blade tip outer surface without affecting the performance of the blade, (c) difficulty to collect data from inaccessible areas, $(d)$ possibility of losing measurement due to surface deformation, and $(e)$ many are not portable. ${ }^{11,76}$ Portability being the ability to move the sensor from one wind turbine to another without difficulty or stopping the wind turbine.

\subsection{Noncontact methods in monitoring wind turbines blades}

Various noncontact SHM sensors have been suggested including laser based, infrared thermography, and microwave, for SHM damage detection like cracks and blade delamination. ${ }^{21-23}$ Infrared thermography is based on the common knowledge that working components increase their temperature as they start to malfunction. The method captures this temperature change for damage location; it is however not appropriate for early fault detection because temperature changes occur slowly. In addition, this noncontact is generally applicable when the wind turbine is not rotating. ${ }^{69}$ The methods however are mainly laboratory based and vary significantly during testing and design of wind turbines blades. However, they may face applicative challenges when applied for onshore in-field rotating wind turbines. Laser-based methods generally include Laser Doppler vibrometer (LDV) and continuous-scan Laser Doppler vibrometer (CSLDV).

In Stanbridge and Ewins,$^{20}$ an LDV is utilized to provide the mode shape of a structure or its deflection by scanning its deflection at a discrete point. The mode shape is achieved by demodulating the output signal through multiplying it by in-phase and quadrature signals at the given excitation frequency. The errors in using LDV are mainly attributed to nonlinearity of the deflection mirror drive system, input signal distortion, and speckle dropout. ${ }^{20}$ These contribute to the measurement errors making LDV's unsuitable for measurement of out-of-plane vibration of rotating wind turbine blades. In addition, LDV's cannot measure deflections for objects moving beyond $24.5 \mathrm{~m} / \mathrm{s}$; wind turbine blades tips tend to travel at beyond $50 \mathrm{~m} / \mathrm{s}$.

Another approach using LDV involve integrating photogrammetry with LDV ${ }^{6}$ suggests use of photogrammetry of deflection of a fixed laser point being compared with the measured deflections of the LDV results. The camera is placed on the movable structures, immediately in front of it being a measurement panel to which a laser beam from the LDV impinges. The LDV is located in a fixed location. By tracking the movement of the laser dot on the screen, the video camera can acquire the displacement experienced by the structure.

Another light-based systems are the laser displacement systems. ${ }^{5}$ In these system, a laser system is attached to the central beam (or tower) that holds the rotating blade. Operating at radio bands of 2.4 GHz, $915 \mathrm{MHz}$, or $868 \mathrm{MHz}$, a pin-point laser is beamed to the tip of the blade or aimed at a point where its expected deflection should reach. Changes different from the expected deflections will result in changes in the laser echo return being different and hence reveal the deflection magnitude. Laser Doppler vibrometers has a lower signal to noise ratio and does not scan the whole area of the blade. It also can be retrofitted into existing system at no great cost. However, if faces a challenge due to the wind turbine blade change direction to face wind from another direction. This implies it has to be installed all around the tower circumferences or at least in dominant wind directions. 
A study's proposal for a $\mathrm{CSLDV}^{77}$ to attempt to overcome the LDV defect were inconclusive as the wind turbine was in a parked position. A wind turbine requires wind speed greater than the cut-in wind speed of $3.5 \mathrm{~m} / \mathrm{s}$ for at least 10 minutes before it releases the parking brake and starts to generate electricity. Thus, the CSLDV provided results for a wind turbine not in actual operating mode. Similar studies with tracking LDV ${ }^{11,78}$ also utilized parked wind turbines. A further challenge with using the LDV type noncontact sensors was the large number of averaged data sets required in order to get reasonable results.

Another noncontact methodology is the photogrammetric/vision-based approaches. In a novel study, ${ }^{20}$ use is made of vision-based displacement measurement system employing photographs and template matching/registration techniques. Essentially the system takes photographs (or videos) and assess each previous and current frame to determine displacement based on a predetermined separation distances between camera and target. It however faces a challenge that all the points on the target surface must have equal depth of fields. The system is also affected by heat haze and camera own vibrations.

Lastly, is the use of microwave radiowaves. Though functionally similar to the GBR is the use of microwaves blade tip clearance, ${ }^{7}$ it involves a probe emitting a continuous electromagnetic wave at $24 \mathrm{GHz}$ to measure displacements of up to one-half of the radiating wavelength, which is $6 \mathrm{~mm}$. The system is particularly suited for measurement of deflection monitoring in extremely elevated temperature gas turbine engines.

In, Yang et al and He et $\mathrm{al}^{22,23}$ a number of noncontact SHM are suggested including laser based, thermography, and microwave, for identification of cracks and blade delamination. The methods however are mainly laboratory based and vary significantly during testing and design of wind turbines blades. However, they may face applicative challenges when applied for in-field rotating wind turbines. In Stanbridge and Ewins, ${ }^{20}$ an LDV provides mode shape of a structure by scanning its deflection at a discrete point. The mode shape is achieved by demodulating the output signal through multiplying it by in-phase and quadrature signals at the given excitation frequency. The errors in using LDV are mainly attributed to nonlinearity of the deflection mirror drive system, input signal distortion, and speckle drop-out. ${ }^{20}$ These contribute to the measurement errors making LDV's unsuitable for measurement of out-of-plane vibration of rotating wind turbine blades. In addition, LDV's cannot measure deflections for objects moving beyond $24.5 \mathrm{~m} / \mathrm{s}$; wind turbine blades tips tend to travel at beyond $50 \mathrm{~m} / \mathrm{s}$.

Other studies ${ }^{77}$ using CSLDV to attempt to overcome this were inconclusive as the wind turbine was in parked position. A wind turbine requires wind speeds greater than the cut-in wind speed of $3.5 \mathrm{~m} / \mathrm{s}$ for at least 10 minutes before it releases the parking brake and starts to generate electricity, not in actual operating mode. Similar studies with tracking LDV ${ }^{11,78}$ also utilized parked wind turbines. Further, a large number of averaged data sets will be required in order to get reasonable results. In this study, the GBR was utilized in actual operating mode as it generates electricity.

\section{Review of GBR for SHM of Blades}

In radar (Radio Detection and Ranging), short bursts of radio energy are transmitted and reflected from the target as an echo. The radar signals are generated by the transmitter and received by a sensitive receiver. Directional antennas are used in radar to transmit the pulse and receiving the echo. Different techniques used in ranging and detection include monostatic ( 1 antenna used for 
both the transmitter and receiver) and quasi-monostatic (collocated transmit and receive antennas), bistatic (noncollocated transmit and receive antennas), and multistatic (multiple transmit and receive antennas).

The attraction of GBR comes from its ability to operate in any weather or light conditions, work day and night, its better spatially-distributed information, ${ }^{79}$ and its greater flexibility in operation and parameter acquisition. Furthermore, GBR has the ability to assess both fast and slow deformations. ${ }^{80}$ Unbalanced parameters monitoring for wind-turbine blades has normally been done using contact methods for mainly discrete point measurements.

The role of SHM in dealing with the fatigue and emergent emphasis of aeroelasticity phenomenon like flutter is critical in integrating EoC conditions into SHM framework. A review of various SHM approaches by Loh et $\mathrm{al}^{13}$ suggested that VBDD methods provide the best practices for wind turbines SHM. Other studies, ${ }^{12}$ however, suggest residual or differential imaged-based signal analysis as being superior. For both approaches, damage occurrence (level 1 damage detection) ${ }^{14}$ can be achieved, however, ${ }^{12}$ indicates that damage localization (level 2 damage detection) can be achieved only with the residual approach for real-life operating wind turbines.

\subsection{VBDD-SHM for blades using GBR}

The first use of radar for deflection monitoring of a wind turbine is mentioned in a patent, ${ }^{81}$ but no practical implementation was seemingly realized at that time. A previous 2008 study ${ }^{82}$ used a GBR with a central frequency of 16.75 and a $350 \mathrm{MHz}$ bandwidth to measure tower deflection. The study employs the use of time-frequency series statics and the modal frequency CPs for the tower at different distances between GBR and wind turbine as well as for different EoCs: stationary to dynamic where the blades are rotating as well as for light and strong wind situations. The study was able to show the capability of the GBR to determine the natural frequency of the tower as well as its deflection. However, a deliberate effort was made to place the GBR in a manner to avoid Doppler effects of rotating wind turbine blades. Consequently, deflection as well natural frequencies of the blades were not captured.

In Zhang et al, ${ }^{57}$ the use of ultra-wideband (UWB) operating between 3.1 to $5.3 \mathrm{GHz}$ is used to determine the deflections of the wind turbine blade tip using a contact approach. Two UWB antennas are attached to the blade root and 1 UWB antenna at the blade tip (Figure 1). Each blade has this radar system attached. The distance between $\mathrm{T} 1$ and $\mathrm{T} 3$ is estimated by the time it takes the first UWB pulse to move from $T 3$ to $A$ and $T 1$ to $B$, then a triangulation is undertaken to determine blade deflection. A similar method has a 2018 patent applied for in Vangen et al. ${ }^{83}$ 


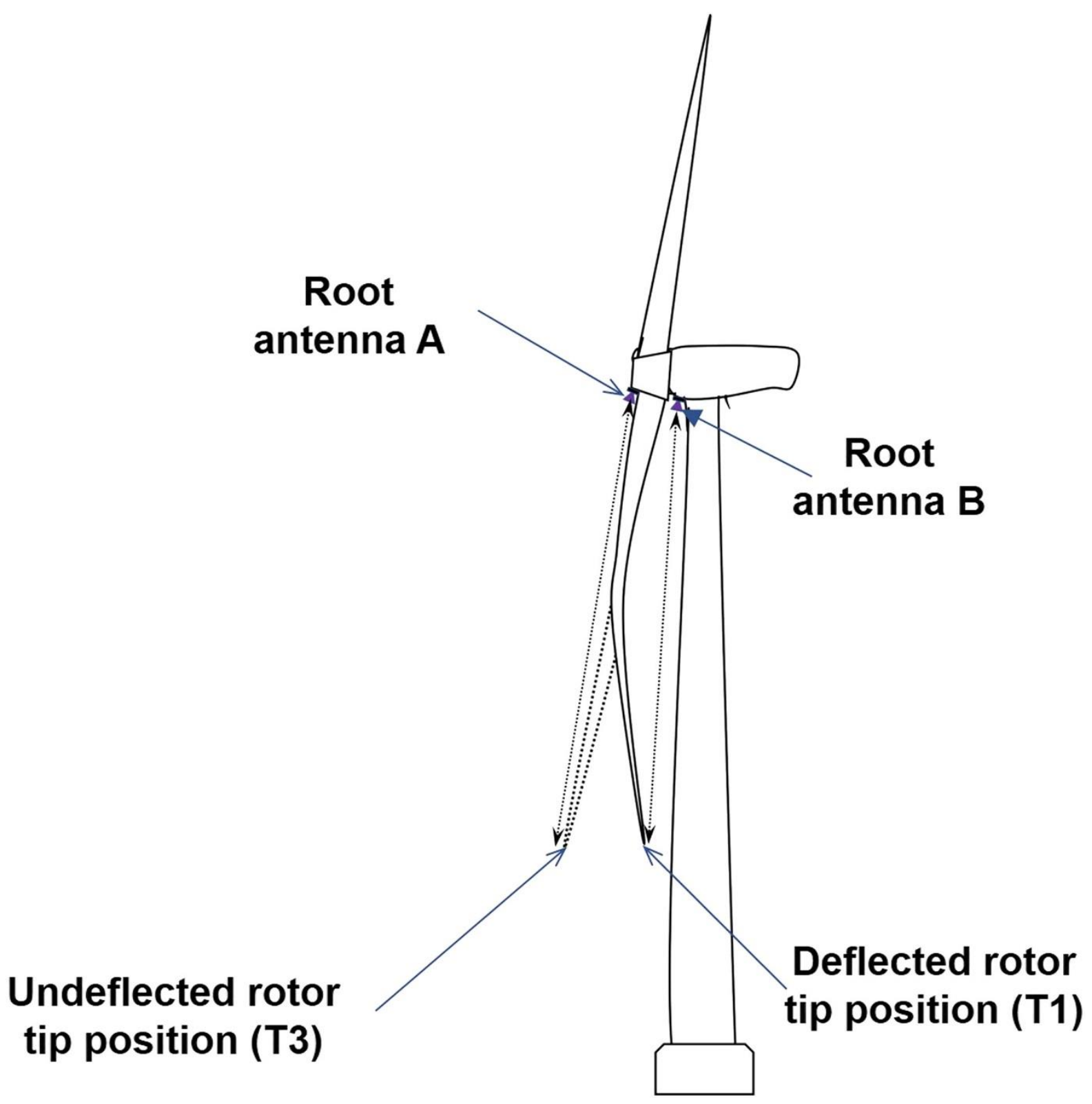

Figure 1 Deflection monitoring using contact radar

The choice of a lower band is attributed to lower cost and commercial availability but has 3 main sources of errors that create specific challenges to using this "contact" radar method are amplitude variation of the first pulse used to determine the rotor root-tip (T3 to T1) distance possible interaction with the blade shell material due to the close proximity between the antenna and the blade. ${ }^{84}$ Secondly such a system will affect aerodynamic properties of an operating wind turbine, and thus cannot be used on large scale or on wind turbines that must continue operation. Lastly, first pulse may suffer interference and cancellation arising from multipath (reflections and surface waves).

The multiple error sources are first, the glass fibre that has a dielectric permittivity of 4.4 and loss tangent of 0.025 , with blade chord changing from $5 \mathrm{~cm}$ at the tip to around $2 \mathrm{~m}$ at the blade root, with the blade shell thickness ranging from $7 \mathrm{~mm}$ to several centimetres, respectively. This creates a shadowing of the signal shadowing/attenuation as it travels from T3 to A and T1 to B (Figure 1) due to the blade tapering and possible scattering. ${ }^{57}$ 
The signal attenuation (multipath) is further investigated in Zhang et al ${ }^{84}$ by installation of $60-\mathrm{cm}$ internal absorber plate from the internal antenna that's inside the blade tip. The advanced method however faces a number of implementation challenges including (1) it cannot be applied to already existing wind turbine blades; (2) the impact of putting an antenna and an absorber plate may need investigation especially in situation of using different composites matrix to make the blades; (3) the impacts of EoC's like wet blade surfaces, ice accretion, and temperature variations measurements is not factored during measurements; and lastly, (4) actual blade frequency is not captured in this method.

An alternative approach to the UWB is shown in a patent application ${ }^{83}$ for a quasi-monostatic radar (1 with 2 antennas for receiving and transmitting, respectively) that is attached to the tower. The Doppler radar unit emits radar signal and receive the backscattered reflected signal from the blade. It then analyses the Doppler shift to determine the blade velocity as it moves towards or away from the tower; additional analysis of the Doppler information will provide parameters like period and amplitude of the rotor blade vibration. An additional claim under this patent is the possibility of having a set of radars along the length of the tower and/or radars that linked to the nacelle and so rotate as the nacelle rotates. No commercial viability of this system could be ascertained.

Interestingly, a previous patent ${ }^{85}$ claims a smart wind turbine deflection sensor. This consist of 3 sensors, 2 within the blade and 1 attached to the tower. The blade sensors are accelerometers and strain gauges, while the sensor attached to the tower would be a laser, radar, or ultrasonic sensor. The need for the 3-sensor typology is premised on the deviation of the cumulative measurement errors of the 2 sensors for the out-of-plane deflection of the rotor blade. Hence, the third stationary sensor affixed to the tower acts as control in the event of such deviation. Using the sensor, an assessment can then be made if the blade is at a risk of striking the tower or not. Seemingly patent ${ }^{83}$ then focusses on the development of this stationary sensor based on radar signals.

Another 2013 study ${ }^{40}$ had a GBR being used to determine the tower deflection of parked (nonrotating) wind turbine tower. The study suggested then that GBR measurements should be limited to points of the tower lower than the blade tips or the blades be stopped in order to obtain the real tower deflection. The study thus presents static tower monitoring. Its limitation being that for better understanding of the EoCs-based SHM, a dynamic state of rotating blades is best.

Efforts to measure a wider range of EoCs by incorporating the rotating blades was attempted by a 2013 study ${ }^{86}$ In this case, a joint time frequency simulation is undertaken and verified on a scaled down version of the wind turbine using a vector network analyser (VNA). The VNA collects the data in continuous wave format at $11 \mathrm{GHz}$ with a sampling rate of $22 \mathrm{GHz}$. The study provides the simulated blade results in a joint time frequency spectrograms for $(a)$ blade circular motions, $(b)$ blade in-plane vibrations, $(c)$ blade out of plane vibrations, $(d)$ blade flexing, and $(e)$ tower vibrations. The simulated results indicate frequency range of between +40 to $-40 \mathrm{~Hz}$, while VNA measurements show frequency range of $\pm 5 \mathrm{~Hz}$. The study essentially sought to demonstrate the possibility of modelling higher order vibration motions on the blade; however, the VNA was unable to fully capture the frequency magnitude properly.

In a 2016 study, ${ }^{37}$ the concept of frequency-modulated continuous-wave (FMCW) Doppler radar employed in a network formation for SHM is presented. The study however is undertaken in a simulated environment but anchored from experimental results from a 2015 study using a $24 \mathrm{GHz}$ hand held radar. ${ }^{87}$ Spectrograms on the time-Doppler frequency domain are presented for different aspect angles. The simulation results are compared with results from a handheld K-band radar used for Doppler-based SHM in a 2015 study. ${ }^{87}$ The handheld radar employs a simple low-end analouge to 
digital converter similar to the one used in a computer sound card. The radar was held directly in front of the wind turbine blade rotation plane, then at $45^{\circ}$ and lastly at $15^{\circ}$. The study concluded that the best results are obtained when the radar is at $15^{\circ}$ to the blade rotation plane (what in this study we refer to as an orthogonal angle that is approaching $90^{\circ}$ to the nacelle side). Again, the results presented show a time-Doppler frequency spectrogram.

A recent study ${ }^{88}$ has shown that the internal spar structure of the wind turbine affects the radar signature when the blade is observed from trailing or leading edge of the rotor blade. This reinforces the need to put the GBR at an orthogonal/spectral direction to rotor rotational axis, ie, the GBR is at $90^{\circ}$ to the drive train of the turbine.

Further, another recent 2017 study ${ }^{89}$ employed the use of hybrid C band FMCW radar to extract the wind turbine blade Doppler information related to the blade velocity as well as determine the range (hence blade deflection). The study presents results of $\mathrm{C}$-band $5.8 \mathrm{GHz}$ radar for the $3.7-\mathrm{m}$-diameter small wind turbine and K-band $24 \mathrm{GHz}$ GBR's for monitoring of blades of the $47-\mathrm{m}$ wind turbines. The study results are presented in time-Doppler frequency. Basic CP features, namely, time-frequency data are extracted. More detailed CP features like modal frequency or even undertaking a hypothesis testing analysis are not done, nor relating it to SHM of wind turbines undertaken.

Another recent 2017 study ${ }^{39}$ compares laboratory measurements from a $5.8 \mathrm{GHz}$ C-band CW Doppler radar with that of $24 \mathrm{GHz}$ K-band radar using time-Doppler frequency graphs on damaged and undamaged wind turbine blades. The horn antennas for the both radars are placed in tight formation of a $2 \times 2$ matrix and operated concurrently. Such a set up provides a challenge in terms of antenna interference with the transmitted and reflected radio waves unless a corrective algorithm is implemented. The study focusses on the blade tip deflection in a laboratory situation and does not consider the changing environmental conditions such as temperature or more specifically wind speeds.

It will be noted that the design of a wind turbine rotor length is limited by how much deflection it can undergo. For unloaded conditions, (Figure 2 ) the distance between maximum blade tip displacement up to point $\mathrm{T} 2$ and the tower should not be less than $30 \%$ of the distance between the mast and the T3. Blade deflection measurement of the displacement from T3 to T2, faces a challenge, as currently used sensor cannot measure the displacement accurately $y^{57}$ for wind turbines in operation. A third sensor may be necessary to enable better accuracy, hence the need of a remote GBR. 


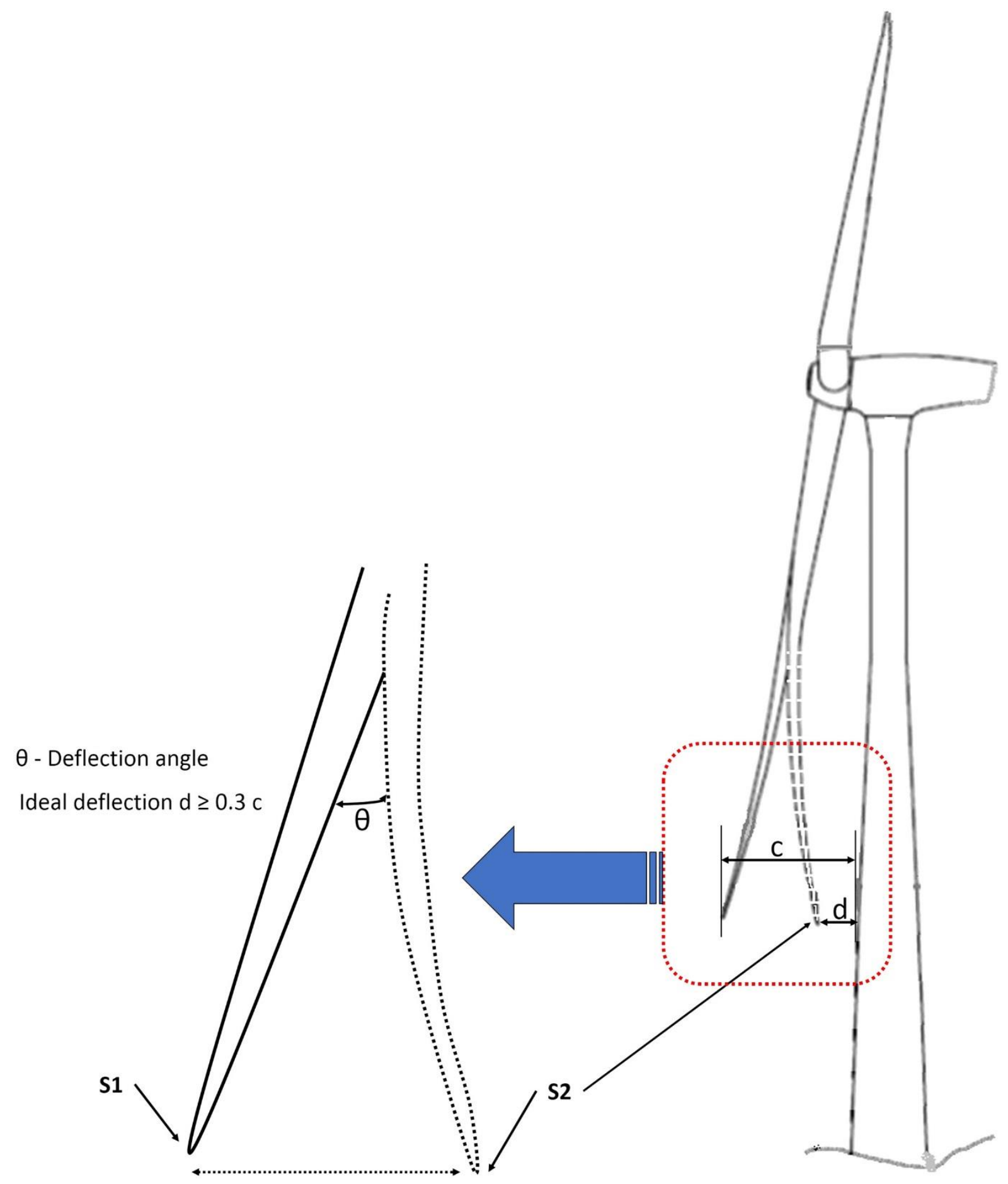

Figure 2 Deflection of rotor blade tip

Based on the foregoing results, the unbalanced parameters can be extracted by frequency domain and time domain manipulations of the diverse frequency returns between the minimum frequency $\left(f_{L}\right)$ and maximum frequency $\left(f_{H}\right)$ for a quasi-monostatic radar as shown by Ozdemir. ${ }^{90}$

The different delays/ranges of the backscattered waves distinguish them from each other allowing sections of the blade or tower to be identified in the corresponding 1D or range profile, ie. profile versus time $(t)$. This is obtained by match-filtering the backscattered signals with the transmitted signals or stretch processing. 
The limitation of the FMCW is that to obtain the phase information and velocity; the radar has to be turned off on alternate scans. In addition, it sends an impulse directly in the time domain, whereas the stepped frequency CW radar synthesize an effective bandwidth in the frequency domain. Two spectrogram results are presented in the time-frequency domain. The study indicates that GBR for near field SHM should employ high frequencies for better resolutions. This will require a much more refined range resolution for this more studies will be required in this direction. ${ }^{37}$

\subsection{Guided wave-based SHM for blades using GBR}

In a laboratory-based experiment described in Liu et al, ${ }^{14}$ a bistatic Ka radar operating at 33.4 to $36.0 \mathrm{GHz}$ is installed at the tower and acquires echoes when the blade is at 6-o'clock position to enable SHM using 3-dimensional damage localization. Essentially, the methodology employs a guided wave-based $\mathrm{SHM}^{13}$ using differential signal analysis that subtracts the currently acquired image from a prior image of an intact/undamaged structure. This essentially means no contact sensor is utilized in the system. For data acquisition and analysis, a glass fibre composite structure of $0.8 \times 0.3 \times 0.01 \mathrm{~m}$ is placed on a pedestal and imaged. The system achieves a localization error of $\pm 0.15 \mathrm{~m}$ ( $\pm 18.75 \%$ error along the longest side of structure).

The study suggests that method would provide more information than the normal vibration-based SHM approaches. Further that monitoring of frequencies will only identify relatively large defects, but information on damage location can be obtained only in special cases like this. It may be borne in mind that radar was scanning a small stationary structure, in reality, it will need to scan possibly a large wind turbine blade during operation that will produce extremely huge image data footprint every 1 to 3 seconds, and the variability of the wind, external loadings, environment, and operating conditions may further impact on the accuracy of the results. Guided wave-based damage detection provide the following advantages including low frequency ambient vibration, affordability, and large scanning of wind turbines blades.

\subsection{GBR theory on blade deflection}

In the guidelines by Ris $\varnothing$ and Veritas, ${ }^{91}$ the aerodynamic loads on a deflecting blade tip as well as axial forces for tower bending are determined. For a blade deflecting in the flap-wise direction, the unit blade load at the blade tip can be determined from Equation 1 as shown in Ris $\varnothing$ and Veritas. ${ }^{91}$

$$
P_{(r)}=\frac{1}{2} \Psi \rho U_{10}^{2} D_{(r)} C_{\max }
$$

with $\rho$ as air density, $D_{(r)}$ the chord length of the blade at distance $r$ from the hub to the tip, and $C_{\max }$ is the maximum typical values for lift coefficient or the drag coefficient. It ranges between 1.3 and 1.5; $U_{10}$ is the average 10-minute binned wind for 50-year wind speed at a height $h$ above ground, and $\psi$ is the quasi-static gust factor. ${ }^{91}$

To use a radar, the coherent waves of frequency $f$ are emitted and interact with a surface moving or deflecting surface at velocity $u$, resulting in a change or shift of $f$-formally called the Doppler shift $\left(f_{D}\right)$, which is proportional to the target radial velocity (Equation 2$)^{8,90,92,93}$, where $u \cdot \cos \vartheta$ is the velocity component along the radial axis.

$f_{D}=\frac{2 u}{\lambda} \cos \theta$

Using the idea that the damage and normal or abnormal changes in blade deflection (blade tip deflection) will cause detectable changes in the modal properties, then the backscattered signal can be processed to recover the Doppler information, and from it, the natural frequencies as well as 
mode shapes ${ }^{8,92}$ can be extracted. These methods provide a very accurate approach to contactless real-time SHM.

\subsection{Time and frequency manipulations of GBR return signals}

A quasi-monostatic radar has 2 antennas, 1 for transmitting radio waves and the other to receive them, located adjacent to each other, but the separation distance $d_{s}$ between the antenna's is far much less than the distance $(R)$ between the receiver and the target $\left(d_{s} \ll R\right)$ when compared with a bistatic radar. ${ }^{94}$ Consequently, the equation to determine the maximum range $\left(R_{\max }\right)$ for monostatic radar is employed for quasi-monostatic radar ${ }^{94,95}$ is given by Equation 3.

$R_{\max }=\sqrt[4]{\left(\frac{P_{t} G_{t} G_{r} \lambda^{2} \sigma}{(4 \pi)^{3} P_{r=\min }}\right)}$,

where $P_{r_{-} \min }$ is the minimum received power in Watts at the receiver antenna that would allow target detection, $P_{t}$ is the transmitted power in Watts at the transmitter antenna, $G_{r}$ and $G_{t}$ are the antenna gains for the receiver and the transmitter, respectively, while $\lambda$ is the radar signal wavelength in metres and $\sigma$ is the radar cross-section area in square metres.

To measure deflection, the radar must be able to distinguish the 2 maximum points (S1 and S2) of wind turbine blade deflections as the blades oscillate back and forth (Figure 2). This is achieved by ensuring that 2 distinct pulses are returned through having the difference in range $\Delta R=R_{s 2}-R_{s 1}$ that is greater than or equal to $\mathrm{ct}^{95}$ (Equation 4).

$\Delta r_{\max }=\sum_{i=1}^{N} \frac{c \tau}{2}=\frac{N c}{2 B^{\prime}}$

Where $c$ is the velocity of light, the pulse width $(\tau)$ is the time taken by the radar to hit the target and return, $N$ is the total number of range bins or cells, and $B$ is the radar bandwidth of the transmitted signal. $\Delta r_{\max }$ is the maximum range that can be viewed by the GBR. It should be greater than the length of the target to avoid ambiguity. ${ }^{90}$ The bandwidth can be adjusted as required by the measurement. For the best distinction between distinct parts of the rotor blade as it deflects, $\Delta r$ should be minimized.

\section{Case Study}

\subsection{Case study setup}

Globally, the design of wind turbine blades follows approved certification standards that allow for blades design with regard to material strength, structural stability, and blade tip deflection based on Equation 1 for fatigue damage as well as for ultimate strength. ${ }^{96}$ Consequently, the distance $d$ from blade tip to the outside of the tower (Figure 3 ) is used inter-alia as a determinant of the safety of wind turbines and its subsequent certification. Usually, this displacement is taken to probably occur during some extreme conditions while the wind turbine is in operation; therefore, studying of the wind-turbine blade-tip deflection calculation method in Equation 1 and its safety is essential and internationally provided for as shown in wind-turbine design standards. ${ }^{96}$ For certification purposes, the distance $d$ (minimum distance between blade tip and mast) must be greater or equal to 0.3 times $c$ (Figure 3). 

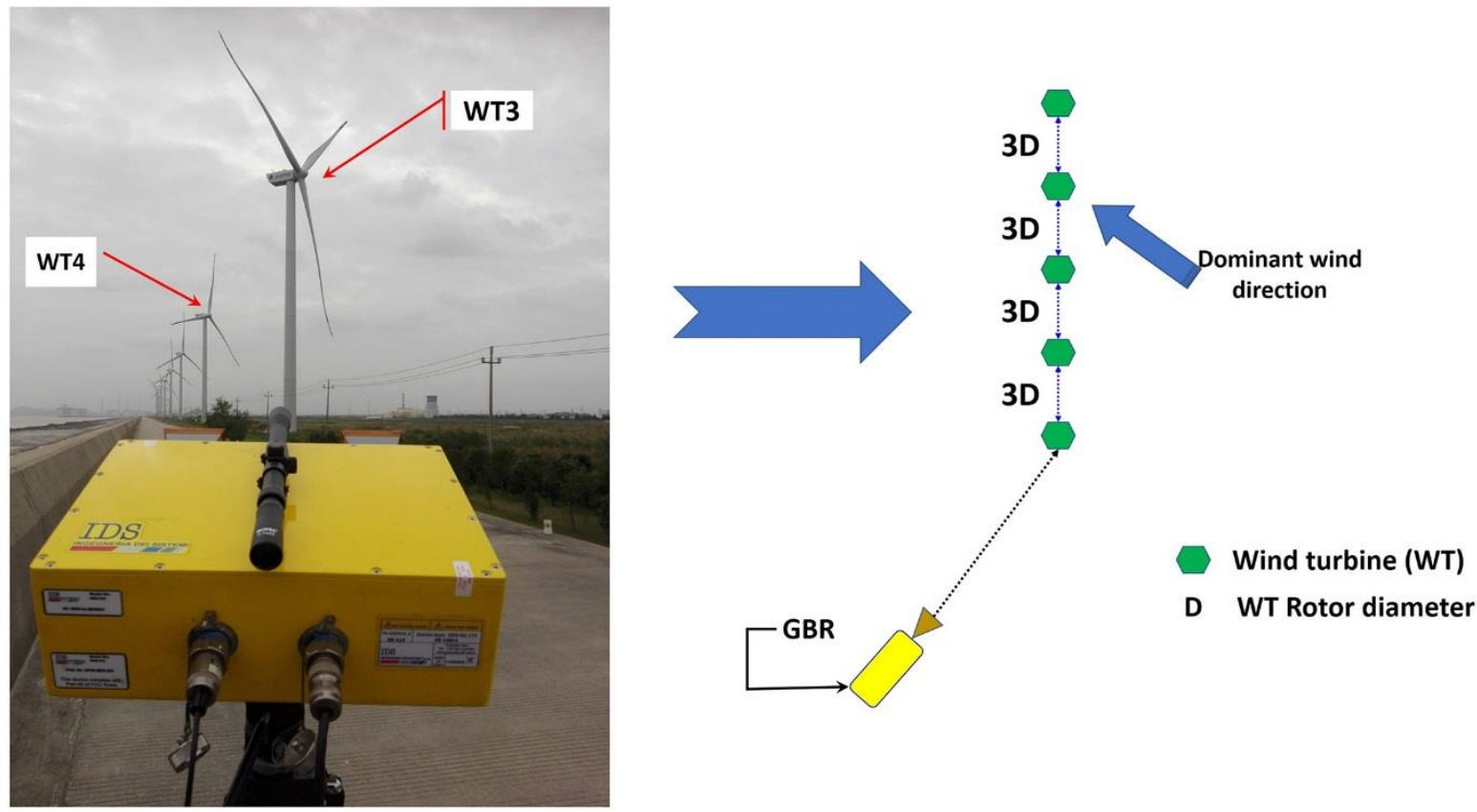

Figure 3 Orthogonal placement of the ground-based radar (GBR)

The GBR used in this study was an IBIS-L system operating in Ku band with a $R_{\max }$ of 1-km, image resolution in distance of $0.75 \mathrm{~m}$, angular resolution of $4.3 \mathrm{mrad}$, and accuracy in measuring displacement in the viewing direction of $0.001 \mathrm{~m}$ for SNR $>50 \mathrm{~dB} .{ }^{97} \mathrm{~A}$ transmitting as well as a receiving IBIS-type 3 (IBIS - H15) antennae, with a maximum gain of $15 \mathrm{dBi}$ was utilized. They had a horizontal antenna beam polarization at $29^{\circ}$ and vertical polarization at $25^{\circ}$. Main beam at $-3 \mathrm{~dB}$, maximum gain was utilized.

The wind park consisting of 14 wind turbines is located at latitude $N 30^{\circ} 39^{\prime} 53.7^{\prime \prime}$ and longitude $\mathrm{E}$ $121^{\circ} 13^{\prime} 14.1^{\prime \prime}$, with the GBR placed at ( $\left.\mathrm{N} 30^{\circ} 39^{\prime} 58.51^{\prime \prime}, \mathrm{E} 121^{\circ} 13^{\prime} 24.86^{\prime \prime}\right)$, and its antennae tilted at $15^{\circ}$ to face the wind turbine nacelle (Figure 2 and Figure 3 ). The GBR was however tilted to $10^{\circ}$ when facing middle of wind turbine tower. The GBR emits radio waves in Ku band in stepped frequencies, and the returned echoes is picked up by the receiving antenna. For best results, the GBR measurements must be taken at 2 different time instances, and data extracted from the same EoCs cluster, say similar wind speeds bins.

In this study, measurement of the blade tip deflection was undertaken by focussing the main beam radio signals of an orthogonally placed GBR at almost the middle of the tower (Figure 3). The reflected/back-scattered signals are then measured in the time domain to obtain the change in range and hence the deflection. A transform is then undertaken on the results of the time-domain to frequency domain to enable acquisition of the natural frequencies of the blade.

\subsection{Case study results}

The GBR resonant natural frequencies are identified at $0.45 \pm 5 \% \mathrm{~Hz}$ and $0.9 \pm 5 \% \mathrm{~Hz}$ are within the range of the Bladed $^{\circledR}$ design frequency of the turbine of $0.49 \pm 5 \% \mathrm{~Hz}$ and $0.88 \pm 5 \% \mathrm{~Hz}$. The measured GBR frequencies are rounded off to 2 significant figures. In Table 2, the shaded yellow part represents the actual GBR measurements obtained from the CP features with the third column representing the error bar range with a 5\% range. The last 3 rows of the table present the results as obtained from the statistical model development (design values). It can be seen that the GBR measurements correlate quite closely with the design values. 


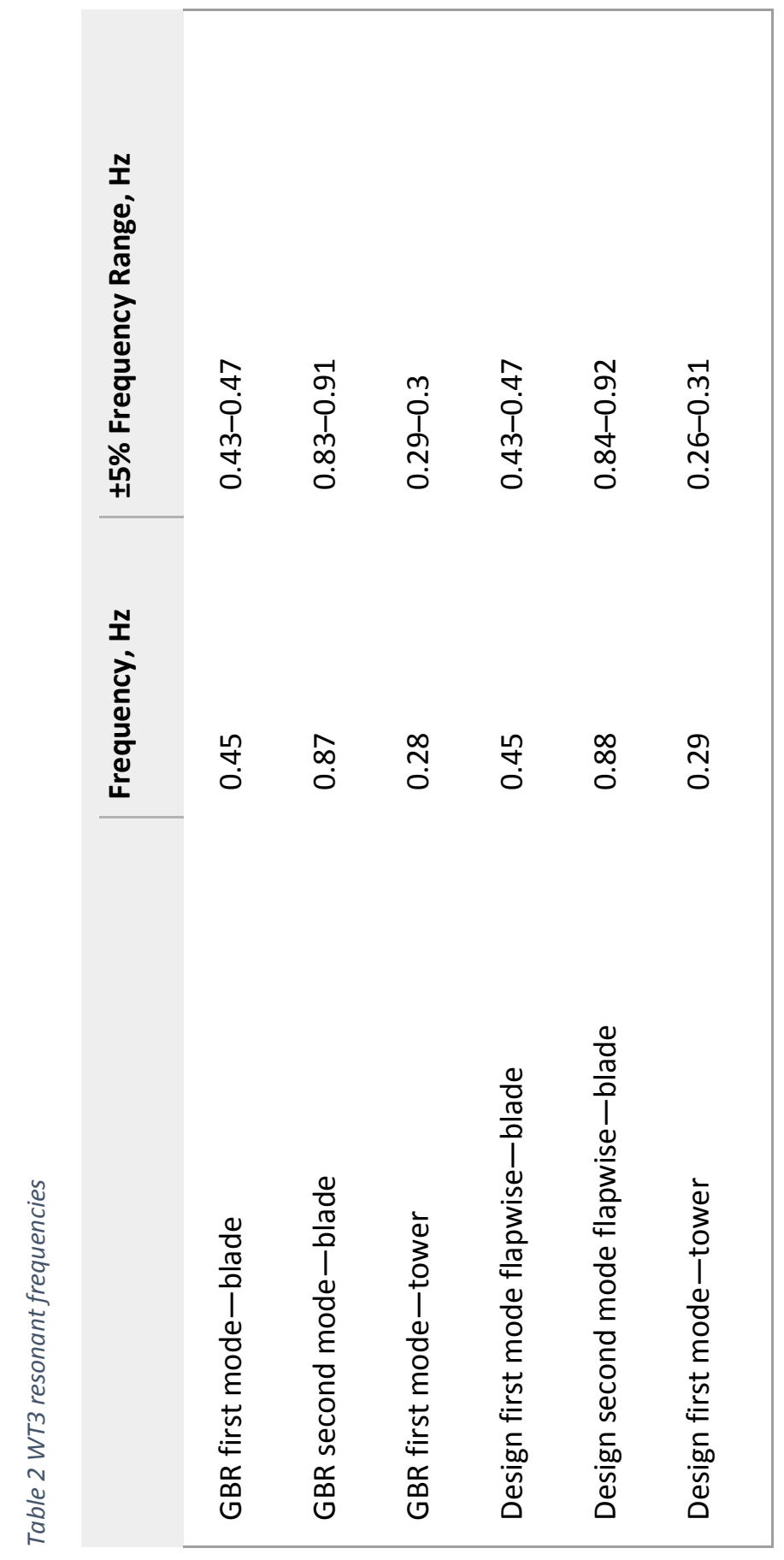




\section{Conclusion}

Structural health monitoring of typical and atypical unbalanced parameters in rotating in-field wind turbines enables assessing of vibrations and hence better structural understanding. The use of a GBR for SHM of wind turbines unbalanced parameters is a potential growing field with that enables a novel, fast, simplified, and more precise understanding of rotating systems in hydropower stations and wind turbines. It can also be applied to the rotating turbines of hydropower plants and other load-bearing stressed structures like dams and bridges.

This paper has dealt with 2 aspects: $(a)$ a review of the state of the art of contact and noncontact sensors for monitoring the wind turbine rotor blades and $(b)$ presented a novel technique that can be applied to monitor the blades and towers of wind turbines. The novel technique consists of monitoring the deflection of the rotor blades by estimating the unbalanced parameters (natural frequency and mode shapes) to provide an understanding of the structural integrity of the system by SVD. Furthermore, this technique is contactless and uses a GBR system that acquires the unbalanced parameters in under 5 minutes. The parameters can then be assessed to know if the system is at risk of fatigue damage by comparisons with previous results of a healthy state.

The review demonstrates GBR capabilities in-field and in-service blade tests. The GBR can measure deflections in structures with amplitudes around a micron. This implies that with an acquisition frequency of between $100 \mathrm{~Hz}$ to $400 \mathrm{~Hz}$, a GBR may measure the unbalanced parameters of wind turbines since the natural frequencies of the blades and tower rarely exceed $10 \mathrm{~Hz}$ for its $1 \mathrm{P}$ up to $3 \mathrm{P}$ natural frequencies. ${ }^{98}$

For modal analysis, further work is required to fine-tune the output-only modal analysis to stochastic processes of the type experienced by a rotating wind turbine in an atmospheric turbulence field and the simultaneous periodic deterministic excitation originating from mean wind shear and tower shadow. An investigation into whether or not it is possible to extract supplemental information of value for modal damping characteristics ${ }^{42}$ during wind turbine operation will also need consideration. To achieve this and based on the aforementioned case studies including preliminary work in Luo et al, ${ }^{99}$ the main applicative areas where GBR may contribute in the wind energy field in monitoring unbalanced parameters are shown in Table 2 . These are in development and testing of blades and towers, condition health monitoring, maintenance and operation, and finally in verification of simulations.

The study has additionally addressed 2 knowledge gaps: first is the applicative use of GBR to provide data of unbalanced parameters within the wind turbine 3-tier SHM framework and secondly the validation of GBR results with accelerometers and numerical simulation. The study further demonstrates GBR use for monitoring during blade design and testing can replace or complement accelerometers or photogrammetry approaches. Further is its portability, monitoring of unbalanced parameters, and fatigue damage assessment for in-field operating wind turbines blades composite materials - such blades are normally difficult to assess using ordinary contact sensors.

In conclusion, GBR can be applied for remote condition monitoring for on-shore wind turbines blades and mast. However, more experiential studies will need to be undertaken to determine the veracity of GBR applications for wind turbines in offshore situations where vertical subsidence of the sea surface plays a role. 


\section{Acknowledgements}

The authors acknowledge the financial support from the International Doctoral Innovation Centre, Ningbo Education Bureau, Ningbo Science and Technology Bureau, and the University of Nottingham. This work was also supported by the Ningbo Science and Technology Bureau as part of the International Academy for the Marine Economy and Technology (IAMET) project Structural Health Monitoring of Infrastructure in the Logistics Cycle (2014A35008). It was also supported by Zhejiang Provincial Natural Science Foundation of China under Grant No. LY16D040001" (本研究得 到浙江省自然科学基金资助, 项目编号为 LY16D040001"). Finally, the authors acknowledge permission granted by the Zhejiang Datang International Pinghu windpower company to monitor wind turbines 1, 2, 3, and 4 using GBR and other sensors as well as the provision of SCADA data for the wind turbines 1 to 3 .

\section{Funding information}

Zhejiang Provincial Natural Science Foundation of China, Grant/Award Number: LY16D040001; Ningbo Science and Technol-ogy Bureau; University of Nottingham; Ningbo Science and Technology Bureau, Grant/AwardNumber: 2014A35008; Ningbo Education Bureau; International Doctoral Innovation Centre.

\section{References}

1 Council GWE. Global Wind Report: Annual Market Update of 2015.Global wind energy council; 2016.

2 Howison J, Thomas J, Ekici K. Aeroelastic analysis of a wind turbine blade using the harmonic balance method. Wind Energy. 2018;21(4):226-241.

3 Heilmann C, Grunwald A, Melsheimer M. Wuchtige Differenzen. In: Erneuerbare Energien-Das Magazin. Berlin: Berlinwind GmbH; 2013.

4 Xie J, Yin P, Shi W, et al. Corrosion mechanism of E-glass of chemical resistance glass fiber in acid environment. J Wuhan Univ Technol Mater Sci Ed. 2016;31(4):872-876.

5 Meng J, Wang Y. A Review on Artificial Aging Behaviors of Fiber Reinforced Polymer-matrix Composites. In MATEC Web of Conferences.EDP Sciences; 2016.

6 Okeniyi JO, Omotosho OA, Popoola API, Loto CA. Phyllanthus muellerianus and C6H15NO3 synergistic effects on $0.5 \mathrm{M} \mathrm{H} 2 \mathrm{SO}$-immersed steel-reinforced concrete: implication for clean corrosion-protection of wind energy structures in industrial environment. In AIP Conference Proceedings. AIP Publishing; 2016.

7 Pryor SC, Barthelmie RJ. Climate change impacts on wind energy: a review. Renew Sustain Energy Rev. 2010;14(1):430-437. 
8 Ciang CC, Lee J-R, Bang H-J. Structural health monitoring for a wind turbine system: a review of damage detection methods. Meas Sci Technol. 2008;19(12). 122001

9 James T, Goodrich A. Supply chain and blade manufacturing considerations in the global wind industry. Nat Renew Energy Lab. 2013.

10 Lin Y, Tu L, Liu H, Li W. Fault analysis of wind turbines in China. Renew Sustain Energy Rev. 2016;55:482-490.

11 Li D, Ho SCM, Song G, Ren L, Li H. A review of damage detection methods for wind turbine blades. Smart Mater Struct. 2015;24(3). 033001

12 Van Overschee P, De Moor B. Subspace identification for linear systems: theoryimplementation-applications. Springer Science \& Business Media; 2012.

13 Loh C-H, Hsueh W, Tu YC, Lin JH, Kuo TJ. Vibration-based damage assessment of structures using signal decomposition and two-dimensional visualization techniques. Struct Health Monit. 2018. 1475921718765915

14 Liu YC, Loh CH, Ni YQ. Stochastic subspace identification for output-only modal analysis: application to super high-rise tower under abnormal loading condition. Earthquake Eng Struct Dyn. 2013;42(4):477-498.

15 Beganovic N, Söffker D. Structural health management utilization for lifetime prognosis and advanced control strategy deployment of wind turbines: an overview and outlook concerning actual methods, tools, and obtained results. Renew Sustain Energy Rev. 2016;64:68-83.

16 Ruan J, et al. Structural health monitoring of wind turbine blade using piezoceremic based active sensing and impedance sensing. In Networking, Sensing and Control (ICNSC), 2014 IEEE 11th International Conference on. IEEE; 2014.

17 Cooperman A, Martinez M. Load monitoring for active control of wind turbines. Renew Sustain Energy Rev. 2015;41:189-201.

18 Ragheb M. Safety of wind systems. 2011; Disponible à l'adresse http://netfiles.uiuc.edu/mragheb/www/NPRE

19 Carroll J, McDonald A, Dinwoodie I, McMillan D, Revie M, Lazakis I. Availability, operation and maintenance costs of offshore wind turbines with different drive train configurations. Wind Energy. 2017;20(2):361-378.

20 Stanbridge A, Ewins D. Modal testing using a scanning laser Doppler vibrometer. Mech Syst Sig Process. 1999;13(2):255-270.

21 Liu W, Tang B, Jiang Y. Status and problems of wind turbine structural health monitoring techniques in China. Renew Energy. 2010;35(7):1414-1418.

22 Yang R, He Y, Zhang H. Progress and trends in nondestructive testing and evaluation for wind turbine composite blade. Renew Sustain Energy Rev. 2016;60:1225-1250.

23 He Y, Yang R, Zhang H, Zhou D, Wang G. Volume or inside heating thermography using electromagnetic excitation for advanced composite materials. Int J Therm Sci. 2017;111:41-49. 
24 Kirikera GR, Shinde V, Schulz MJ, Ghoshal A, Sundaresan M, Allemang R. Damage localisation in composite and metallic structures using a structural neural system and simulated acoustic emissions. Mech Syst Sig Process. 2007;21(1):280-297.

25 Tang J, Soua S, Mares C, Gan TH. An experimental study of acoustic emission methodology for in service condition monitoring of wind turbine blades. Renew Energy. 2016;99:170-179.

26 Saracin A, Negrila A, Cosarca C, Diluesca C, Savu D. Investigations on the use of terrestrial radar interferometry for bridges monitoring. Int Multidiscip Sci GeoConf. 2016;2:375-382.

27 Luzi G, Crosetto M. Building monitoring using a ground-based radar. Enc Earthquake Eng. 2014;113.

28 Pieraccini M. Extensive measurement campaign using interferometric radar. J Perform Constr Facil. 2016;31(3). 04016113

29 Lukin KA, Mogyla A, Palamarchuk V, et al., Monitoring of St. Sophia Cathedral interior using Kaband Ground Based Noise Waveform SAR, in Proceedings of the 6th Radar Conference (EURAD'09). 2009, EURAD'09: Rome, Italy. p. 215-217.

30 Tarchi $\mathrm{D}$, Rudolf $\mathrm{H}$, Pieraccini $\mathrm{M}$, Atzeni $\mathrm{C}$. Remote monitoring of buildings using a groundbased SAR: application to cultural heritage survey. Int J Remote Sens. 2000;21(18):3545-3551.

31 Pasquale AD, Corsetti M, Guccione P, et al. Ground-based SAR interferometry as a supporting tool in natural and man-made disasters. in Towards Horizon 2020. EARSeL; 2013.

32 Hamasaki T, Zhou Z-S, Sato M. Development and applications of an interferometric ground-based SAR System.

33 Zhang B, Ding X, Werner C, et al. Dynamic displacement monitoring of long-span bridges with a microwave radar interferometer. ISPRS J Photogramm Remote Sens. 2018;138:252-264.

34 Rödelsperger S, Meta A. MetaSensing's FastGBSAR: ground based radar for deformation monitoring. Proc SPIE 9243, SAR Image Analysis, Modeling, and Techniques, 2014.9243 (XIV): p. 924318-924318-8.

35 Marchisio M, Piroddi L, Ranieri G, Calcina SV, Farina P. Comparison of natural and artificial forcing to study the dynamic behaviour of bell towers in low wind context by means of ground-based radar interferometry: the case of the Leaning Tower in Pisa. J Geophys Eng. 2014;11(5):055004.

36 Gentile C, Bernardini G. An interferometric radar for non-contact measurement of deflections on civil engineering structures: laboratory and full-scale tests. Struct Infrastruct Eng. 2010;6(5):521-534.

37 Muñoz-Ferreras J-M, Peng Z, Tang Y, Gómez-García R, Liang D, Li C A step forward towards radar sensor networks for structural health monitoring of wind turbines. in Radio and Wireless Symposium (RWS), 2016 IEEE. 2016. IEEE.

38 Corucci L, Working principles of the FastGBSAR F.X. Ochieng, editor. 2016, MetaSensing BV: Online

39 Moll J, Arnold P, Mälzer M, et al. Radar-based structural health monitoring of wind turbine blades: the case of damage detection. Struct Health Monit. 2017. 1475921717721447

40 Pieraccini M. Monitoring of civil infrastructures by interferometric radar: a review. Sci World J. 2013;2013:1-8. 
41 Arnold P, Moll J, Malzer M, et al. Radar-based structural health monitoring of wind turbine blades: the case of damage localization. Wind Energy. 2017.

42 Sørensen BF, Bent F, Lading L, et al., Fundamentals for remote structural health monitoring of wind turbine blades-a preproject. 2002.

43 Hameed Z, Hong YS, Cho YM, Ahn SH, Song CK. Condition monitoring and fault detection of wind turbines and related algorithms: a review. Renew Sustain Energy Rev. 2009;13(1):1-39.

44 Winstroth J, Schoen L, Ernst B, Seume JR. Wind turbine rotor blade monitoring using digital image correlation: a comparison to aeroelastic simulations of a multi-megawatt wind turbine. in Journal of Physics: Conference Series 2014. IOP Publishing.

45 Ozbek M, Rixen DJ. Using remote sensing technologies for wind turbine/farm health monitoring. Prog Clean Energy. 2015, Springer;2:1045-1056.

46 Söker H. 2 - Loads on wind turbine blades. In: Advances in Wind Turbine Blade Design and Materials. Woodhead Publishing; 2013:29-58.

47 Mukupa W, Roberts GW, Hancock CM, al-Manasir K. A review of the use of terrestrial laser scanning application for change detection and deformation monitoring of structures. Survey Review. 2016;1-18.

48 Ebert R, Lutzmann P, Scherer C, Scherer-Negenborn N, Göhler B, van Putten F. Laser Vibrometry for Wind Turbines Inspection. In: Advanced Solid State Lasers. Shanghai: Optical Society of America; 2014.

49Grosse-Schwiep M, Piechel J, Luhmann T. Measurement of rotor blade deformations of wind energy converters with laser scanners. in Journal of Physics: Conference Series. 2014. IOP Publishing.

50 Mostböck A, Petryna Y. Structural vibration monitoring of wind turbines. in 9th International Conference on Structural Dynamics, EURODYN. 2014.

51 Roberts GW, Brown C, Meng X. Deflection Monitoring of the Fouth Road Bridge by GPS, in ION GNSS 18th International Technical Meeting of the Satellited Division. 2005, ION GNSS: California, USA.

52 Roberts GW, Cosser E, Meng X, Dodson A. High frequency deflection monitoring of bridges by GPS. J Glob Position Syst. 2004;3(1-2):226-231.

53 Bonenberg LK, Hancock C, Roberts GW. Locata performance in a long term monitoring. J Appl Geod. 2013;7(4):271-280.

54 Bonenberg LK. Closely-coupled integration of Locata and GPS for engineering applications. 2014, University of Nottingham.

55 Choudhury M. Analysing Locata Positioning technology for slow structural displacement monitoring application. 2012, PhD thesis, University of New South Wales, Surveying \& Spatial Information Systems.

56 Barlas TK, Van Kuik G. Review of state of the art in smart rotor control research for wind turbines. Prog Aerosp Sci. 2010;46(1):1-27.

57 Zhang S, Jensen T, Franek O, et al. UWB wind turbine blade deflection sensing for wind energy cost reduction. Sensors. 2015;15(8):19768-19782. 
58 Das S, Saha P, Patro SK. Vibration-based damage detection techniques used for health monitoring of structures: a review. J Civ Struct Heal Monit. 2016;6(3):477-507.

59 Häckell MW, Rofles R, Kane MB, et al., Three-tier modular structural health monitoring framework using environmental and operational condition clustering for data normalization: validation on an operational wind turbine system. Proceedings of the IEEE, 2016.104(8): p. 1632-1646.

60 Martinez-Luengo M, Kolios A, Wang L. Structural health monitoring of offshore wind turbines: a review through the statistical pattern recognition paradigm. Renew Sustain Energy Rev. 2016;64:91105.

61 Liu W, Tang BP, Han JG, Lu XN, Hu NN, He ZZ. The structure healthy condition monitoring and fault diagnosis methods in wind turbines: a review. Renew Sustain Energy Rev. 2015;44:466-472.

62 Chase DD, Danai K, Lackner MA, Manwell JF. Detection of damage of wind turbines by signature distances. Int J Progn Health Manag. 2013;4(Special issue):101-114.

63 Hartono D, Halim D, Widodo A, Roberts GW. Comparative Study of Gearbox Fault Diagnosis by Vibration Measurements. in The International Conference on Nanomaterial, Semiconductor and Composite Materials 2016. 2016. online: ICNSCM.

64 Rödelsperger S, Becker M, Gerstenecker C, Läufer G, Schilling K, Steineck D. Digital elevation model with the ground-based SAR IBIS-L as basis for volcanic deformation monitoring. $J$ Geodyn. 2010;49(3-4):241-246.

65 Metternicht G, Hurni L, Gogu R. Remote sensing of landslides: an analysis of the potential contribution to geo-spatial systems for hazard assessment in mountainous environments. Remote Sens Environ. 2005;98(2-3):284-303.

66 Jarosz, A., Zahiri H, Warren M, Sowter A. Utilisation of InSAR for subsidence Monitoring over the caving zone of Underground Metalliferous Mine. in Fifth International Workshop on ERS SAR Interferometry. 2007. Frascati, Italy: ERS SAR.

67 Wymore ML, van Dam JE, Ceylan H, Qiao D. A survey of health monitoring systems for wind turbines. Renew Sustain Energy Rev. 2015;52:976-990.

68 García Márquez FP, Tobias AM, Pinar Pérez JM, Papaelias M. Condition monitoring of wind turbines: techniques and methods. Renew Energy. 2012;46:169-178.

69 Tchakoua P, Wamkeue R, Ouhrouche M, Slaoui-Hasnaoui F, Tameghe T, Ekemb G. Wind turbine condition monitoring: state-of-the-art review, new trends, and future challenges. Energies. 2014;7(4):2595-2630.

70 Jensen FM, Falzon BG, Ankersen J, Stang H. Structural testing and numerical simulation of a $34 \mathrm{~m}$ composite wind turbine blade. Compos Struct. 2006;76(1-2):52-61.

71 Rahman M, Ong ZC, Chong WT, Julai S, Khoo SY. Performance enhancement of wind turbine systems with vibration control: a review. Renew Sustain Energy Rev. 2015;51:43-54.

72 Niknam SA, Thomas T, Wesley Hines J, Sawhney R. Analysis of acoustic emission data for bearings subject to unbalance. Int J Progn Health Manag. 2013;4(Special issue):80-89.

73 Gong X, Qiao W. Simulation investigation of wind turbine imbalance faults. In International Conference on Power System Technology; 2010. 
74 Qu L, Liu X, Peyronne G, Chen Y. The holospectrum: a new method for rotor surveillance and diagnosis. Mech Syst Sig Process. 1989;3(3):255-267.

75 Zhou A, Yu D, Zhang W. A research on intelligent fault diagnosis of wind turbines based on ontology and FMECA. Adv Eng Inf. 2015;29(1):115-125.

76 de Azevedo HDM, Araújo AM, Bouchonneau N. A review of wind turbine bearing condition monitoring: state of the art and challenges. Renew Sustain Energy Rev. 2016;56:368-379.

77 Yang S, Allen MS. Output-only modal analysis using continuous-scan laser Doppler vibrometry and application to a $20 \mathrm{~kW}$ wind turbine. Mech Syst Sig Process. 2012;31:228-245.

78 Ozbek M, Rixen DJ. Operational modal analysis of a $2.5 \mathrm{MW}$ wind turbine using optical measurement techniques and strain gauges. Wind Energy. 2013;16(3):367-381.

79 Antonello G, Casagli N, Farina P, et al. Ground-based SAR interferometry for monitoring mass movements. Landslides, J ICL. 2004;1(1):21-28.

80 Metasensing GBSAR RAR. 2016.4.

81 Kildegaard, C., Monitoring the operation of a Wind Energy plant, in https://patentscope. wipo.int/Search/en/detail.jsf;jsessionid=42BB246D1F401DCAC4A763728519 69F2. wapp1nC?docld=WO2005068834\&recNum=1\&maxRec=\&office=\&prevFilter=\&sortOption=\&q ueryString=\&tab=PCT+Biblio, W.I.P.O. (WIPO), Editor. 2006: Denmark.

82 Pieraccini M, Parrini F, Fratini M, Atzeni C, Spinelli P. In-service testing of wind turbine towers using a microwave sensor. Renew Energy. 2008;33(1):13-21.

83 Vangen K, Meum E, Pleym JR. Wind turbine blade vibration detection and radar calibration. 2018, Google Patents.

84 Zhang S, Franek O, Eggers PCF, Byskov C, Pedersen GF. Multipath suppression with an absorber for UWB wind turbine blade deflection sensing systems. IEEE Trans Microw Theory Tech. 2017;65(7):2583-2595.

85 Bosche JV. Wind turbine blade deflection control system. 2007, Google Patents.

86 Naqvi A, Ling H. Time-frequency and ISAR characteristics of wind turbines with higher order motions. Prog Electromagn Res. 2013;143:331-347.

87 Nikoubin T, Muñoz-Ferreras J-M, Gómez-García R, Liang D, Li C. Structural health monitoring of wind turbines using a low-cost portable K-band radar: an ab-initio field investigation. In Wireless Sensors and Sensor Networks (WiSNet), 2015 IEEE Topical Conference on. 2015. IEEE.

88 Livingstone C, Chiu S, Centre D-OR. Ground based radar observations of wind turbines. Ottawa, Canada: Ottawa research institute; 2014:121.

$89 \mathrm{Li} \mathrm{C}$, Peng Z, Huang TY, et al. A review on recent progress of portable short-range noncontact microwave radar systems. IEEE Trans Microw Theory Tech. 2017;65(5):1692-1706.

90 Ozdemir C. Inverse Synthetic Aperture Radar Imaging With MATLAB Algorithms. Wiley; 2012.

91 Ris $\varnothing$ D, Veritas N. Guidelines for design of wind turbines. Det Norske veritas; 2002. 
92 Wujanz D, Röckelein S, Neitzel F, Fröhlich C. On data acquisition of moving objects via kinematic terrestrial laser scanning. In ISPRS Workshop Laser Scanning 2013, ISPR, Editor. 2013: Antalya, Turkey.

93 Prislan R, Svensek D. Laser Doppler Vibrometry and modal testing. Ljubljana; 2008:17.

94 Kolawole M. Radar Systems, Peak Detection and Tracking. Newnes; 2003.

95 Jenn D. Radar fundamentals. Dep Electr Comput Eng. 2007.93943;831.

96 Commission IE. IEC 61400-1: Wind turbines part 1: design requirements. International Electrotechnical Commission; 2005.

97 IDS. IBIS-L System User manual. v Italy: Ingegmeria dei sistemi SpA (IDS) 65; 2010.

98 Van Wingerden J, Hulskamp AW, Barlas T, et al. On the proof of concept of a 'smart'wind turbine rotor blade for load alleviation. Wind Energy. 2008;11(3):265-280.

99 Luo Y, Chen YA, Sun YX, Zhang Q. Narrowband radar imaging and scaling for space targets. IEEE Geosci Remote Sens Lett. 2017;14(6):946-950. 